\title{
Social Activities Domain
}

National Cancer Institute

\section{Source}

National Cancer Institute. Social Activities Domain. NCI Thesaurus. Code C129991.

A domain of the Activity Card Sort (ACS) related to social activities that may be part of an individual's routine such as volunteer work, visiting with friends, and traveling. 